\title{
Editorial Preface for Special Section on Thermal Management
}

\author{
Yuying Yan $^{1} \cdot$ Liang Guo ${ }^{2}$
}

Accepted: 2 November 2020 / Published online: 2 December 2020

(c) China Society of Automotive Engineers (China SAE) 2020

Automotive thermal management technology is critical for achieving higher thermal efficiency, longer component life, better driving stability and comfort of vehicles. With the continuous advances of new energy vehicles (NEVs), the rational design and development of thermal management systems for NEVs become a new challenge for automakers.

With the emergence of novel materials, advanced processes and intelligent control technologies, automotive thermal management systems will be more diversified, efficient, cost-effective and intelligent. Aiming at technical promotion of vehicle thermal management systems, a special section on thermal management is proposed. Thanks for the 16th UK Heat Transfer Conference, which allows some of the authors rewrite the papers and publish on this special section.

The papers, as listed below, cover the topics of innovative thermal management solutions for electrified power train [1], e-motors [1], power batteries [2, 4], IGBTs or invertors $[1,3]$, and air-conditioning systems [5], also include two papers relating to the technology and methods of efficiency improvement of gas vehicle [6,7].

- Thermal management of electrified propulsion system for low-carbon vehicles [1].

- Thermal performance of a micro heat pipe array for battery thermal management under special vehicle-operating conditions [2].
- Thermal analyses of power electronics integrated with vapour chamber cooling [3].

- Thermal management optimization of a lithium-ion battery module with graphite sheet fins and liquid cold plate [4].

- Simulation and analysis of dual-evaporator refrigeration system for electric vehicles [5].

- Micro gas turbine range extender performance analysis using varying intake temperature [6].

- Distributed gas ignition (DGI) using injection strategy for high efficiency and clean combustion under lean condition [7].

The publication of this special section would not be achieved without the meticulous work and joint efforts of all the authors, reviewers and editors. We would like to thank all authors, reviewers and the staff from the editorial office of Automotive Innovation for their hard work and support. Heartly hope this special section can inspire scientific ideas and promote research in the fields of automotive thermal management.

Prof. Yuying Yan

Prof. Liang Guo

Guest editors

Yuying Yan

yuying.yan@nottingham.ac.uk

1 Faculty of Engineering, University of Nottingham, University Park, Nottingham, UK

2 College of Automotive Engineering, Jilin University, Changchun, China 


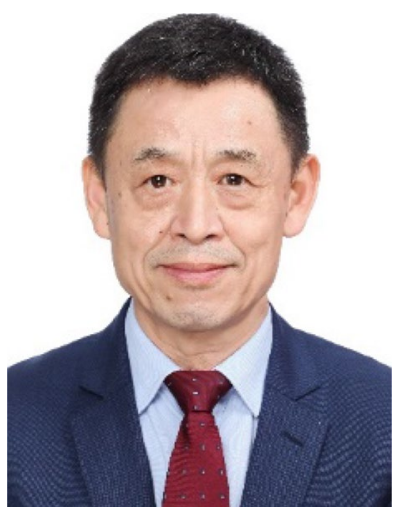

Dr. Yuying Yan is Professor and Chair in Thermofluids Engineering in Faculty of Engineering at University of Nottingham, UK. $\mathrm{He}$ obtained $\mathrm{BSc}$ in Internal Combustion Engine Engineering at Jilin University of Technology in 1982, MSc in Thermal Energy Engineering at Shanghai Institute of Mechanical Engineering in 1986 and $\mathrm{PhD}$ in Mechanical Engineering at City University of London in 1996. He started his academic position in the UK at Nottingham Trent University since 1998 after two years serving as Research Fellow in Chemical \& Process Engineering at University of Surrey. He has joined the University of Nottingham since 2004. His research covers widely ranged areas of fluids \& thermal engineering including heat transfer enhancement, phase changes, surface wetting, nanofluids and nature inspired solutions and energy efficiency, as well as energy storage and thermal management. Over the past 25 years, his research is well founded by UK EPSRC, European Commission, Innovate UK, Royal Society, Royal Academy of Engineering and industrial companies. He is now a lead academic investigator for UK Advanced cooling \& integration of e-Drive project. He has published more than 400 academic papers in refereed journals and conferences, and give more than 50 keynotes presentation in international conferences/workshops. Prof. Yan was EU advanced grant panel member, and is current member of UK EPSRC Peer Review College and UK National Heat Transfer Committee. He is Associate Editor of Case Studies in Thermal Engineering; Editorial Board member of
International Journal of Heat and Mass Transfer, Nature: Scientific Reports, Journal of Bionic Engineering, Thermal Science and Engineering Progress, and Automotive Innovation; Fellow of International Society of Bionic Engineering (ICBE) and World Society of Sustainable Energy Technologies (WSSET).

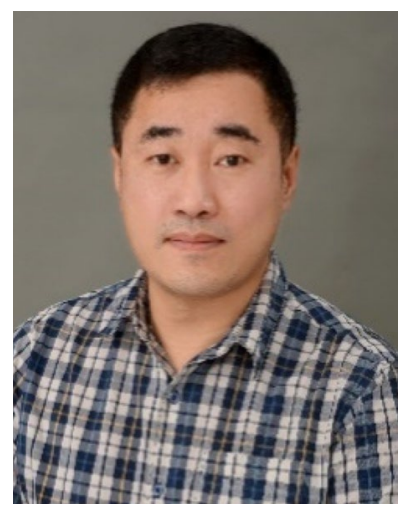

Dr. Liang Guo is a Professor and the Assistant to Dean at the Automotive College of the Jilin University. His research interests include fuel design and combustion optimization of internal combustion engine, process of heat and mass transfer in power machines. He graduated from the University of Nottingham in 2011 with a doctoral degree in Power Engineering, and was a postdoc fellow at the Faulty of Engineering in the University of Nottingham and the Rolls-Royce University Technology Centre in the Loughborough University, during 2011-2014. During these periods he participated in several research projects related to the efficient cooling and thermal management, including the Knowledge Transfer Partner Project, the EU 7th Framework program and several R\&D projects from power companies, such as the Siemens Energy, UK and the Rolls Royce. He has published more than 50 peer-reviewed papers and holds more than 15 patents in the area of power machinery. He is also an Editor-in-chief of a textbook for undergraduates majored in Automotive Engineering. 